\title{
Medial Patellofemoral Ligament Reconstruction in Adolescents Affected by Patellar Instability
}

\author{
Gianluca Testa, Vito Pavone *, Ludovico Lucenti, Giuseppe Condorelli and Giuseppe Sessa \\ Department of Orthopaedics and Traumatologic Surgery, AOU Policlinico-Vittorio Emanuele, Via Plebiscito 628, \\ 95127 Catania, Italy; gianpavel@hotmail.com (G.T.); ludovico.lucenti@gmail.com (L.L.); \\ dott.condorelli@libero.it (G.C.); giusessa@unict.it (G.S.) \\ * Correspondence: vitopavone@hotmail.com; Tel.: +39-095-743-5240; Fax: +39-095-350-611
}

Academic Editor: Nick Caplan

Received: 12 February 2017; Accepted: 28 April 2017; Published: 30 April 2017

\begin{abstract}
Patellar instability is a heterogeneous group of morphological and functional disorders of the knee extensor mechanism. The medial patellofemoral ligament (MPFL) has been recognized as being important in stabilizing the patella and preventing lateral patellar dislocation. Recurrent dislocations in the pediatric population may benefit from surgical intervention. The aim of this study is to retrospectively evaluate adolescent patients treated with surgical reconstruction of medial patello-femoral ligament. Between January 2009 and December 2014, seven patients with patellar instability were treated at the Department of Orthopaedics and Traumatology of the University of Catania, Sicily. Five patients $(71.4 \%)$ were female and two $(28.6 \%)$ were male. The mean age at the time of surgery was $14.9 \pm 1.1$ years (range 13-16 years). All cases were treated with reconstruction of the MPFL. Clinical outcomes and complications were reported. Mean follow-up was $26.1 \pm 10.9$ months (range 12-46 months). Evaluation at two years after surgery identified an average Knee Society Score (KSS) of $94.3 \pm 7.4$ (range 78-100). An excellent result was obtained in six patients (85.7\%) and a good result was obtained in one patient (14.3\%). A recurrence was reported in one patient (14.3\%). This study shows that surgical treatment of patellar instability by reconstruction of MPFL leads to satisfying results at mid-term follow-up.
\end{abstract}

Keywords: patellar instability; recurrent dislocation; adolescents; medial patellofemoral ligament; surgical treatment; reconstruction of medial patellofemoral ligament (MPFL)

\section{Introduction}

Patellar instability is a heterogeneous group of morphological and functional disorders of the knee extensor mechanism, which represents the most common knee injuries in the pediatric population [1-3]. The rates of acute, traumatic patellar dislocation peaks among adolescents 15 to 19 years old, with an incidence of 11.19 people per 100,000 years [4]. Recognized predisposing factors of patellar instability are genu valgum, patella alta, ligament laxity, contracture of the lateral patellar soft tissues, hypoplasia of the lateral femoral condyle, a laterally located tibial tubercle, vastus medialis insufficiency, and abnormal attachment of the iliotibial tract. Furthermore, it is well known that dislocation of the patella can cause patellofemoral pain and degenerative arthritis [5].

The medial patellofemoral ligament (MPFL) has been recognized as being important in stabilizing the patella and preventing lateral patellar dislocation, and thus it is the primary restraint in lateral patellar dislocation [6]. The MPFL contributes to controlling patellar tilt and translation. MPFL distension can be evaluated clinically, based on the patellar apprehension test and on other recently introduced tests. Patellar tilt and translation can be measured on MRI or CT images (taken with the knee extended and the quadriceps contracted or relaxed) [7]. Although non-operative treatment remains the gold standard of treatment after primary patellar dislocation without osteochondral 
fragments [8-10], recurrent dislocations in this population may benefit from surgical intervention. Reconstruction of the MPFL prevents lateral patellar dislocation, reporting good results in the treatment of children [11-13].

The aim of this study is to evaluate retrospectively adolescent patients treated with surgical reconstruction of the medial patellofemoral ligament (MPFL).

\section{Materials and Methods}

\subsection{Patients and Demographics}

Between January 2009 and December 2014, seven patients with patellar instability were treated at the Department of Orthopaedics and Traumatology of the University of Catania.

Five patients $(71.4 \%)$ were female and two $(28.6 \%)$ were male. The mean age at the time of surgery was $14.9 \pm 1.1$ years (range 13-16 years).

In all cases, surgical treatment was required when patellar dislocation had occurred more than twice, after the failure of conservative treatment for an average of six months.

\subsection{Surgical Technique}

All patients first underwent a standard diagnostic arthroscopy to evaluate patellar tracking as well as additional intra-articular pathology. This was followed by open MPFL reconstruction.

For the surgical option, the ipsilateral semitendinosus tendon was harvested in a standard fashion in six cases for the reconstruction of the MPFL, while the gracilis tendon was used in only one case.

The graft was then folded in half. A longitudinal incision was performed between the midline and the medial border of the patella. The medial third of the patella was exposed by subperiosteal dissection. Two holes were drilled on the medial side of the patella and connected with a curved curette. A second tunnel was executed along the patella. Another surgical incision was made anteriorly to the palpable ridge linking the medial femoral epicondyle and the adductor tubercle. A pin was positioned at the insertion site of the MPFL near the medial epicondyle and passed toward the lateral side of the femur. A loop of suture was passed around the pin and through one of the patellar tunnels. The looped end of the graft was inserted into the femoral tunnel and fixed with absorbable interference screw. Next, the free ends of the graft were passed through the retinacular interval and then through the patellar tunnels using a curved suture passer. The free graft arms were successively folded back and sutured on themselves. The graft was fixed at the greatest length, as determined by isometry. Patellar mobility and range of motion were checked. The remnant of the native MPFL was sutured to the graft, and the retinaculum was closed over the graft.

\subsection{Rehabilitation}

In the postoperative period, all patients were immobilized with a kneepad at $30^{\circ}$ flexion for four weeks, after which they followed a rehabilitation protocol. Physical therapy was initiated at one week postoperatively to begin knee range of motion (ROM) in the hinged knee brace. Knee ROM began at $0^{\circ}$ to $30^{\circ}$ and advanced to $0^{\circ}$ to $90^{\circ}$ by six weeks postoperatively. At six weeks postoperatively, the crutches and knee brace were discontinued. At four months after surgery, patients were allowed to run and sporting activity was allowed at six months if the patients demonstrated clinical stability.

\subsection{Clinical Assessment}

Clinical evaluation was assessed at 4, 8 and 12 weeks postoperative, as well as every six months up to two years. The parameters evaluated were: Knee Society Score (KSS), range of motion, pain visual analog scale (VAS), muscle strength with Medical Research Council (MRC) scale, difference of tropism between the two limbs and, finally, the number of relapses after surgery. 


\subsection{Statistical Analysis}

Qualitative data were expressed as absolute frequencies and relative percentages while quantitative data were expressed as mean \pm standard deviation (SD) and range. After the normality of VAS and MRC was tested by the Kolgomorov-Smirnov test, Friedman's test was used to compare VAS and MRC scores between the different times of follow-up, and Wilcoxon singed-rank test was used for post hoc analyses.

\section{Results}

Average follow-up was $26.1 \pm 10.9$ months (range 12-46 months). Evaluation at two years after surgery identified an average KSS score of $94.3 \pm 7.4$ (range 78-100). An excellent result was obtained in six patients $(85.7 \%)$ and a good result was obtained in one patient $(14.3 \%)$ (Table 1$)$.

Table 1. Results of study.

\begin{tabular}{cc}
\hline Patients & 7 \\
\hline Males & $2(28.6 \%)$ \\
\hline Females & $5(71.4 \%)$ \\
\hline Mean Age at the Time of Surgery (Years) & $14.9 \pm 1.1$ (range 13-16) \\
\hline Average Follow-Up (Months) & $26.1 \pm 10.9$ (range 12-46) \\
\hline Mean Knee Society Score & $94.3 \pm 7.4$ (range 78-100) \\
\hline Mean Preoperative Visual Analog Scale & $4.9 \pm 1.3$ (range 3 to 7) \\
\hline Mean Final Follow-Up VAS Scale & $0.3 \pm 0.5$ (range 0 to 1) \\
\hline Recurrences (Patients) & $1(14.3 \%)$ \\
\hline
\end{tabular}

The mean range of motion was from $0 \pm 4$ to $145 \pm 2$. The mean VAS scale reduced from $4.9 \pm 1.3$ (range 3 to 7 ) preoperatively to $0.3 \pm 0.5$ (range 0 to 1 ) at follow-up $(p<0.05)$ (Table 2).

Table 2. Variation of Visual Analog scale at follow-up.

\begin{tabular}{ccccc}
\hline Patients & Preoperative & At $\mathbf{3}$ Months & At $\mathbf{1}$ Year & At 2 Years \\
\hline Patient 1 & 3 & 1 & 1 & 0 \\
Patient 2 & 4 & 0 & 0 & 0 \\
Patient 3 & 5 & 3 & 1 & 0 \\
Patient 4 & 4 & 1 & 3 & 0 \\
Patient 5 & 5 & 0 & 2 & 0 \\
Patient 6 & 6 & 2 & 1 & 1 \\
Patient 7 & 7 & 0 & 2 & 1 \\
\hline Mean & $4.9 \pm 1.3$ & $1.0 \pm 1.2$ & $1.4 \pm 1.0$ & $0.3 \pm 0.5$ \\
\hline
\end{tabular}

The mean MRC scale improved from $3.1 \pm 0.7$ (range 2 to 4 ) preoperatively to $4.9 \pm 0.4$ (range 4 to 5$)$ at follow-up $(p<0.05)$ (Table 3$)$.

Table 3. Variation of Medical Research Council scale at follow-up.

\begin{tabular}{ccccc}
\hline Patients & Preoperative & At 3 Months & At 1 Year & At 2 Years \\
\hline Patient 1 & 2 & 3 & 5 & 5 \\
Patient 2 & 3 & 4 & 5 & 5 \\
Patient 3 & 3 & 4 & 5 & 5 \\
Patient 4 & 3 & 4 & 5 & 5 \\
Patient 5 & 3 & 4 & 5 & 5 \\
Patient 6 & 4 & 5 & 5 & 5 \\
Patient 7 & 4 & 5 & 5 & 5 \\
\hline Mean & $3.1 \pm 0.7$ & $4.1 \pm 0.7$ & $4.6 \pm 0.5$ & $4.9 \pm 0.4$ \\
\hline
\end{tabular}


A significant difference in tropism between the two limbs was noted only in one patient (14.3\%), who had a recurrence four months after surgery.

\section{Discussion}

Patellar instability is characterized by lateral dislocation or subluxation of the patella relative to the femoral trochlea [14,15]. It often occurs in young patients during sporting activities, such as basketball, soccer, and football [4], with associated predisposing factors, these being joint hyperlaxity, lower limb malalignment, external tibial torsion and increased Q-angles $[1,16]$. The traumatic mechanism consists of an internal rotation of the leg relative to a fixed foot, often including simultaneous quadriceps contraction, and more rarely consists of a direct trauma to the medial patellar surface [17]. The anatomical structure involved in this type of injury is represented by MPFL, a fascial band extending from the medial border of the patella to a site near the medial femoral epicondyle [18].

Non-operative treatment represents the gold standard in children and adolescents $[9,10]$, consisting of initial support with a knee immobilizer or brace locked in extension to allow ambulation and early initiation of physical therapy $[15,19]$.

Surgical treatment is indicated in cases of recurrent patellar dislocations or in primary patellar dislocations associated with large $(>5 \mathrm{~mm})$ displaced osteochondral fractures or chondral shear fragments, and/or complete avulsion of the vastus medialis oblique from the patellar insertion site $[10,20-22]$.

There are a lot of bone realignment procedures, finalized to address patellar instability, but they could not be readily used in children and adolescents with open physes because of the likelihood of a growth arrest and consequent axial deformity. Therefore, the younger the child, the greater the risk of patellar instability, with redislocation rates ranging from $7.14 \%$ to $71 \%$ after the primary dislocation [23,24]. Consequently, the tendency of the surgeon is to perform soft tissue-based procedures, respecting the physeal and apophyseal integrity [13]. However, adolescent patients with closed growth plates can safely undergo bone realignment procedures [25]. In the past, several soft tissue procedures, such as the Galeazzi semitendinosus tenodesis [26], the Roux-Goldthwait [27] procedure, and the " 3 -in-1" [28] procedure, were used in children with a high rate of failure and persistence of clinical manifestation [16,29].

The surgical procedure used in all patients of our series was MPFL reconstruction. Although it has been used successfully in adults [30,31], it could be indicated for use in adolescents, because it works toward preserving the original MPFL anatomy [13,32]. The procedure consists of the attachment of a semitendinosus tendon autograft near the proximal medial collateral ligament attachment on the femur, as a proxy for the femoral MPFL insertion site [33]. The reconstruction of the MPFL medial patellofemoral ligament allows for the restoration of normal length and stiffness of the medial soft tissue. Success rates of procedures which restore the medial restraints using different types of grafts and techniques range between 80 and $90 \%$ [34,35]. In our series, we reported a mean success rate of $85.7 \%$, similar to the data provided in the literature.

Optimal use of the technique requires a proper attachment site of the MPFL, as incorrect positioning can result in post-surgical complications in both skeletally mature and immature patients [36,37]. Moreover, a study of Shah et al. [38] reported on the high rate of complication associated with MPFL reconstruction, including patellar fracture, postoperative instability, flexion loss, and pain.

In our series, we reported a failure in one in seven cases (14.3\%), because of a postoperative instability with consequent recurrence four months after surgery, which was dealt with by conservative treatment, based on physical therapy and a stabilizer brace.

\section{Conclusions}

In conclusion, this study shows that surgical treatment of patellar instability with reconstruction of the MPFL leads to satisfying results at mid-term follow-up. Respect for indications during the 
treatment of patellar instability and adequate physiotherapy, regardless of the type of graft used, are crucial. Longer follow-up is needed, because it is important to avoid failure of technique, which could cause recurrent patellar instability and osteoarthritis.

Author Contributions: Gianluca Testa and Vito Pavone conceived and designed the study; Vito Pavone and Giuseppe Condorelli performed surgery; Gianluca Testa and Ludovico Lucenti analyzed the data; Giuseppe Sessa supervised the article; Gianluca Testa wrote the paper.

Conflicts of Interest: The authors declare no conflict of interest.

\section{References}

1. Fithian, D.C. Epidemiology and natural history of acute patellar dislocation. Am. J. Sports Med. 2004, 32, 1114-1121. [CrossRef] [PubMed]

2. Kraus, T.; Švehlík, M.; Singer, G.; Schalamon, J.; Zwick, E.; Linhart, W. The epidemiology of knee injuries in children and adolescents. Arch. Orthop. Trauma Surg. 2012, 132, 773-779. [CrossRef] [PubMed]

3. Chotel, F.; Bérard, J.; Raux, S. Patellar instability in children and adolescents. Orthop. Traumatol. Surg. Res. 2014, 100, S125-S137. [CrossRef] [PubMed]

4. Waterman, B.R.; Belmont, P.J., Jr.; Owens, B.D. Patellar dislocation in the United States: Role of sex, age, race, and athletic participation. J. Knee Surg. 2012, 25, 51-57. [CrossRef] [PubMed]

5. Wada, A.; Fujii, T.; Takamura, K.; Yanagida, H.; Surijamorn, P. Congenital dislocation of the patella. J. Child Orthop. 2008, 2, 119-123. [CrossRef] [PubMed]

6. Kepler, C.K.; Bogner, E.A.; Hammoud, S.; Malcolmson, G.; Potter, H.G.; Green, D.W. Zone of injury of the medial patello-femoral ligament after acute patellar dislocation in children and adolescents. Am. J. Sports Med. 2011, 39, 1444-1449. [CrossRef] [PubMed]

7. Seeley, M.; Bowman, K.; Walsh, C.; Sabb, B.J.; Vanderhave, K.L. Magnetic resonance imaging of acute patellar dislocation in child patterns of injury risk factors for recurrence. J. Pediatr. Orthop. 2012, 2, 145-155. [CrossRef] [PubMed]

8. Smith, T.O.; Donel, S.; Song, F.; Hing, C.B. Surgical versus non-surgical interventions for treating patellar dislocation. Cochrane Database Syst. Rev. 2015, 2, CD008106.

9. Hing, C.B.; Smith, T.O.; Donell, S.; Song, F. Surgical versus non-surgical interventions for treating patellar dislocation. Cochrane Database Syst Rev. 2011, 11, CD008106.

10. Palmu, S.; Kallio, P.E.; Donell, S.T.; Helenius, I.; Nietosvaara, Y. Acute patellar dislocation in children and adolescents: A randomized clinical trial. J. Bone Jt. Surg. Am. Vol. 2008, 90, 463-470. [CrossRef] [PubMed]

11. Deie, M.; Ochi, M.; Sumen, Y.; Yasumoto, M.; Kobayashi, K.; Kimura, H. Medial patello-femoral ligament reconstruction for the treatment of recurrent or habitual dislocation of the pa tella in children. J. Bone Jt. Surg. Br. Vol. 2003, 85B, 887-890.

12. Bicos, J.; Fulkerson, J.P.; Amis, A. Current concepts review: The medial patellofemoral ligament. Am. J. Sports Med. 2007, 35, 484-492. [CrossRef] [PubMed]

13. Nelitz, M.; Dreyhaupt, J.; Reichel, H.; Woelfle, J.; Lippacher, S. Anatomic reconstruction of the medial patellofemoral ligament in children and adolescents with open growth plates: Surgical technique and clinical outcome. Am. J. Sports. Med. 2013, 41, 58-63. [CrossRef] [PubMed]

14. Buckens, C.F.; Saris, D.B. Reconstruction of the medial patellofemoral ligament for treatment of patellofemoral instability: A systematic review. Am. J. Sports Med. 2010, 38, 181-188. [CrossRef] [PubMed]

15. Colvin, A.C.; West, R.V. Patellar instability. J. Bone Jt. Surg. Am. Vol. 2008, 90, 2751-2762. [CrossRef] [PubMed]

16. Hsiao, M.; Owens, B.D.; Burks, R.; Sturdivant, R.X.; Cameron, K.L. Incidence of acute traumatic patellar dislocation among active-duty United States military service members. Am. J. Sports Med. 2010, 38, 1997-2004. [CrossRef] [PubMed]

17. Larsen, E.; Lauridsen, F. Results of conservative treatment of patellar dislocations. Acta Orthop. Belg. 1982, 48, 455-462. [PubMed]

18. Amis, A.A.; Firer, P.; Mountney, J.; Senavongse, W.; Thomas, N.P. Anatomy and biomechanics of the medial patellofemoral ligament. Knee 2003, 10, 215-220. [CrossRef]

19. McConnell, J. Rehabilitation and nonoperative treatment of patellar instability. Sports Med. Arthrosc. Rew. 2007, 15, 95-104. [CrossRef] [PubMed] 
20. Camp, C.L.; Krych, A.J.; Dahm, D.L.; Levy, B.A.; Stuart, M.J. Medial patellofemoral ligament repair for recurrent patellar dislocation. Am. J. Sports Med. 2010, 38, 2248-2254. [CrossRef] [PubMed]

21. Chotel, F.; Knorr, G.; Simian, E.; Dubrana, F.; Versier, G. Knee osteochondral fractures in skeletally immature patients: French multicenter study. Orthop. Traumatol. Surg. Res. 2011, 97, S154-S159. [CrossRef] [PubMed]

22. Christiansen, S.E.; Jakobsen, B.W.; Lund, B.; Lind, M. Isolated repair of the medial patellofemoral ligament in primary dislocation of the patella: A prospective randomized study. Arthroscopy 2008, 24, 881-887. [CrossRef] [PubMed]

23. Apostolovic, M.; Vukomanovic, B.; Slavkovic, N.; Vuckovic, V.; Vukcevic, M.; Djuricic, G.; Kocev, N. Acute patellar dislocation in adolescents: Operative versus nonoperative treatment. Int. Orthop. 2011, 35, 1483-1487. [CrossRef] [PubMed]

24. Lewallen, L.W.; McIntosh, A.L.; Dahm, D.L. Predictors of recurrent instability after acute patellofemoral dislocation in pediatric and adolescent patients. Am. J. Sports Med. 2013, 41, 575-581. [CrossRef] [PubMed]

25. Grannatt, K.; Heyworth, B.E.; Ogunwole, O.; Micheli, L.J.; Kocher, M.S. Galeazzi semitendinosus tenodesis for patellofemoral instability in skeletally immature patients. J. Pediatr. Orthop. 2012, 32, 621-625. [CrossRef] [PubMed]

26. Marsh, J.S.; Daigneault, J.P.; Sethi, P.; Polzhofer, G.K. Treatment of recurrent patellar instability with a modification of the Roux-Goldthwait technique. J. Pediatr. Orthop. 2006, 26, 461-465. [CrossRef] [PubMed]

27. Oliva, F.; Ronga, M.; Longo, U.G.; Testa, V.; Capasso, G.; Maffulli, N. The 3-in-1 procedure for recurrent dislocation of the patella in skeletally immature children and adolescents. Am. J. Sports Med. 2009, 37, 1814-1820. [CrossRef] [PubMed]

28. Balcarek, P.; Jung, K.; Ammon, J.; Walde, T.A.; Frosch, S.; Schüttrumpf, J.P.; Stürmer, K.M.; Frosch, K.H. Anatomy of lateral patellar instability: Trochlear dysplasia and tibial tubercle-trochlear groove distance is more pronounced in women who dislocate the patella. Am. J. Sports Med. 2010, 38, 2320-2327. [CrossRef] [PubMed]

29. Khormaee, S.; Kramer, D.E.; Yen, Y.M.; Heyworth, B.E. Evaluation and management of patellar instability in pediatric and adolescent athletes. Sports Health 2015, 7, 115-123. [CrossRef] [PubMed]

30. Calvo Rodri'guez, R.; Figueroa Poblete, D.; Anastasiadis Le Roy, Z.; Etchegaray Bascur, F.; Vaisman Burucker, A.; Calvo Mena, R. Reconstruction of the medial patellofemoral ligament: Evaluation of the clinical results of autografts versus allografts. Rev. Esp. Cir. Ortop. Traumatol. 2015, 59, 348-353. [CrossRef]

31. Weinberger, J.M.; Fabricant, P.D.; Taylor, S.A.; Mei, J.Y.; Jones, K.J. Influence of graft source and configuration on revision rate and patient-reported outcomes after MPFL reconstruction: A systematic review and meta-analysis. Knee Surg. Sports Traumatol. Arthrosc. 2016. [CrossRef] [PubMed]

32. Hohn, E.; Pandya, N.K. Does the Utilization of Allograft Tissue in Medial Patellofemoral Ligament Reconstruction in Pediatric and Adolescent Patients Restore Patellar Stability? Clin. Orthop. Relat. Res. 2017, 475, 1563-1569. [CrossRef] [PubMed]

33. Drez, D., Jr.; Edwards, T.B.; Williams, C.S. Results of medial patellofemoral ligament reconstruction in the treatment of patellar dislocation. Arthroscopy 2001, 17, 298-306. [CrossRef] [PubMed]

34. Ellera Gomes, J.L.; Stigler Marczyk, L.R.; Cesar de Cesar, P.; Jungblut, C.F. Medial patellofemoral ligament reconstruction with semitendinosus autograft for chronic patellar instability: A followup study. Arthroscopy 2004, 20, 147-151. [CrossRef] [PubMed]

35. Nomura, E.; Horiuchi, Y.; Kihara, M. A mid-term follow-up of medial patellofemoral ligament reconstruction using an artificial ligament for recurrent patellar dislocation. Knee 2000, 7, 211-215. [CrossRef]

36. Bollier, M.; Fulkerson, J.; Cosgarea, A.; Tanaka, M. Technical failure of medial patellofemoral ligament reconstruction. Arthroscopy 2011, 27, 1153-1159. [CrossRef] [PubMed]

37. Tanaka, M.J.; Bollier, M.J.; Andrish, J.T.; Fulkerson, J.P.; Cosgarea, A.J. Complications of medial patellofemoral ligament reconstruction: Common technical errors and factors for success: AAOS exhibit selection. J. Bone Jt. Surg. Am. Vol. 2012, 94, e87. [CrossRef] [PubMed]

38. Shah, J.N.; Howard, J.S.; Flanigan, D.C.; Brophy, R.H.; Carey, J.L.; Lattermann, C. A systematic review of complications and failures associated with medial patellofemoral ligament reconstruction for recurrent patellar dislocation. Am. J. Sports Med. 2012, 40, 1916-1923. [CrossRef] [PubMed]

(C) 2017 by the authors. Licensee MDPI, Basel, Switzerland. This article is an open access article distributed under the terms and conditions of the Creative Commons Attribution (CC BY) license (http:/ / creativecommons.org/licenses/by/4.0/). 